\title{
Comparação de métodos de seleção de genitores e populações segregantes aplicados ao melhoramento de trigo
}

\author{
Adérico Júnior Badaró Pimentel $\left({ }^{1 *}\right)$; Guilherme Ribeiro $\left({ }^{2}\right)$; Moacil Alves de Souza $\left({ }^{1}\right)$; \\ Lisandra Magna Moura ('); Josiane Cristina de Assis ( $\left.{ }^{3}\right)$; Juarez Campolina Machado ( ${ }^{4}$ ) \\ (1) Universidade Federal de Viçosa (UFV), Departamento de Fitotecnia, 36571-000 Viçosa (MG), Brasil. \\ (2) Universidade Federal do Pampa (UNIPAMPA), Faculdade de Agronomia, 97650-000 Itaqui (RS), Brasil. \\ (3) Centro Universitário do Planalto de Araxá, 38180-084 Araxá (MG), Brasil. \\ (4) Embrapa Gado de Leite, 36038-330 Juiz de Fora (MG), Brasil. \\ (*) Autor correspondente: adericojr@yahoo.com.br
}

Recebido: 7/fev./2013; Aceito: 6/maio/2013

\begin{abstract}
Resumo
Os métodos utilizados para seleção de cruzamentos em uma cultura não necessariamente são apropriados para outras. O presente trabalho teve como objetivo avaliar a aplicação da análise dialélica, da diversidade genética, da média parental e do método de Jinks e Pooni na seleção de genitores e populações segregantes superiores para o caráter rendimento de grãos em trigo. Para isso, foram conduzidos dois experimentos. Os tratamentos foram dispostos em látice (experimento I) e em blocos casualizados com informação de indivíduo dentro da parcela (experimento II). Avaliaram-se 12 genitores e as 36 populações segregantes na geração $F_{3}$ resultantes do cruzamento desses genitores em esquema de dialelo parcial. A aplicação das metodologias avaliadas produziu resultados distintos. A média parental e a diversidade genética isoladamente não constituem método de predição eficiente. A aplicação da metodologia de Jinks e Pooni apresenta limitação de ordem prática, não se adequando ao sistema de cultivo do trigo. Dentre as metodologias avaliadas, a análise dialélica constitui o método mais promissor para identificação de genitores e populações segregantes superiores.
\end{abstract}

Palavras-chave: Triticum aestivum, predição do potencial genético, capacidade de combinação, rendimento de grãos.

\section{Comparison of methods for selection of parents and segregating populations applied to wheat breeding}

\section{Abstract}

The methods used for selecting crosses in one crop species are not necessarily appropriate for others. The present study aimed to evaluate the application of diallel analysis, genetic diversity, parental average, and the Jinks and Pooni method for the selection of parents and superior segregating populations for the grain yield character in wheat. Thus, two experiments were conducted and the treatments were arranged in lattice (experiment I) and randomized blocks with individual information within the plot (experiment II). Twelve parental individuals and 36 segregating populations in the $F_{3}$ generation resulting from the crossing of these parents in a partial diallel arrangement were evaluated. The application of the evaluated methodologies led to distinct results. The parental average and genetic diversity alone are not efficient prediction methods. The methodology of Jinks and Pooni presents practical limitation because it is not adequate for wheat crop system. Among the evaluated methodologies, diallel analysis is the most promising method for the identification of parents and superior segregating populations.

Key words: Triticum aestivum, prediction of the genetic potential, combining ability, grain yield.

\section{INTRODUÇÃO}

A seleção de genitores e de populações segregantes constitui a primeira etapa no processo de melhoramento. Desta depende o sucesso das demais etapas e, consequentemente, a eficiência do programa, sendo uma das decisôes de maior importância a ser tomada pelo melhorista (Bertan et al., 2007; Pereira et al., 2007). A despeito da relevância dessas decisôes, pouco foi elucidado e publicado sobre as bases científicas da seleção de germoplasma (Borém e Miranda, 2009), tornando a escolha de genitores uma das maiores dificuldades encontradas pelos melhoristas (LoRENCETTI et al., 2005).

$\mathrm{Na}$ ausência dessas informaçôes, muitas populaçōes segregantes são formadas e avaliadas anualmente nos programas de melhoramento. Entretanto, nem todas 
possuem potencial genético suficiente para extração de genótipos com constituição genética superior (BARROso e Hoffmann, 2003). Isso dificulta o progresso genético da cultura, pois parte dos recursos disponíveis é utilizada na geração e condução de populaçôes que não trarão resultados satisfatórios.

O melhorista deve atuar em populaçóes que possuam média alta associada a grande variabilidade genética para o caráter sob seleção. Esses parâmetros populacionais são determinados pela capacidade de combinação entre os genitores envolvidos em cada cruzamento (RAMALHO et al., 2012), que pode ser classificada em capacidade geral (CGC) e capacidade específica de combinação (CEC) (Sprague e TATUM, 1942).

A CGC representa o comportamento médio de um genitor em suas combinaçôes híbridas, e seu efeito é função da ação de genes de efeito predominantemente aditivos (Sprague e Tatum, 1942). Os efeitos aditivos são responsáveis pela proporção da variação fenotípica que pode ser transmitida para as sucessivas geraçôes, sendo, portanto, responsável pelo desempenho das linhas puras obtidas em cada população quando a homozigose é alcançada (RAmalho et al., 1988). A CEC está relacionada com efeitos gênicos não aditivos (Sprague e TATUm, 1942) e indica o grau de complementaridade entre os genitores envolvidos nos cruzamentos (Cruz et al., 2012). O efeito da CEC é útil para os melhoristas de plantas autógamas, pois sua magnitude indica a dimensão da variabilidade que pode ser expressa em cada população, esperando-se maior probabilidade de obtenção de segregantes transgressivos quando os efeitos da CEC forem elevados (BARELLI et al., 2000).

Neste contexto, a utilização de metodologias eficientes na seleçấo de genitores e predição do comportamento de populaçóes segregantes torna-se ferramenta necessária aos melhoristas (VALÉRIO et al., 2009). O conhecimento prévio do potencial das populaçóes geradas evita que as pouco promissoras sejam formadas ou que estas sejam eliminadas em geraçóes precoces. A partir disso, maior ênfase pode ser dada à seleção dentro das populaçôes superiores, aumentando a probabilidade de sucesso e evitando a perda de tempo e recurso financeiro.

Diversas metodologias foram desenvolvidas para esses fins. Algumas baseiam-se apenas em informaçôes dos genitores, como a média parental e a diversidade genética, enquanto outras fundamentam-se no comportamento das progênies oriundas dos cruzamentos, abrangendo a análise dialélica e o método proposto por Jinks e Pooni (1976). Outra diferença observada é que alguns desses métodos consideram apenas a média do caráter em questão para predição, enquanto outros consideram a média e a variância.

Haja vista que cada cultura apresenta suas particularidades, os métodos empregados em uma cultura não necessariamente são apropriados para outra. Assim, é preciso que estudos sejam realizados para avaliar a eficiência e adequação das metodologias disponíveis à rotina do processo de melhoramento de cada cultura. Alguns trabalhos foram conduzidos com esse intuito em algumas culturas, tais como Oliveira et al. (1996) e Mendonça et al. (2002), com feijão comum, e Lorencetti et al. (2006), com aveia. Objetivou-se com este trabalho avaliar a aplicação da análise dialélica, da diversidade genética, da média parental e do método de Jinks e Pooni (1976) na seleção de genitores e populaçôes segregantes de trigo para o caráter rendimento de grãos.

\section{MATERIAL E MÉTODOS}

Para a obtenção do material experimental, 12 cultivares/ linhagens (Tabela 1) foram cruzadas em esquema de dialelo parcial, obtendo-se 36 híbridos. Para formação dos grupos, as cultivares/linhagens foram estratificadas em função da complementaridade para potencial produtivo, qualidade industrial de farinha, adaptabilidade e estabilidade de produçáo e outras características de relevância agronômica. As sementes $F_{1}$ foram multiplicadas em casa de vegetaçáo, e a geraçáo $\mathrm{F}_{2}$, conduzida a campo. Em 2009, as sementes $\mathrm{F}_{3}$ foram utilizadas para implantação de dois experimentos.

Tabela 1. Relação dos genitores de trigo, com seus respectivos cruzamentos e instituição responsável, cruzados em esquema de dialelo parcial para obtenção das populaçôes segregantes avaliadas em Viçosa (MG), 2009

\begin{tabular}{|c|c|c|c|}
\hline Grupo & Genitores & Cruzamento & Instituição \\
\hline \multirow{6}{*}{ I } & Embrapa 22 & Veery“S”/3/Klein Toledo“S”/PAT19//Moncho/ Jupateco 73 & EMBRAPA \\
\hline & Embrapa 42 & LAP689/MS7936 & EMBRAPA \\
\hline & BRS 254 & Embrapa 22*3/Anahuac 75 & EMBRAPA \\
\hline & BRS 264 & Buckbuck/Chiroca//Tui & EMBRAPA \\
\hline & IAC 24-Tucuruí & IAS51/SON64/YAQUI50E/GB/2*CIANO & IAC \\
\hline & IAC 364-Tucuruí III & $\begin{array}{l}\text { IAS58/IAS55//IALS“S”/3/IAC5/4/ALD“S”// } \\
\text { IAS58/8.1034.A//ALD/5/CNR/6/BUC/7/IAC24 }\end{array}$ & IAC \\
\hline \multirow{6}{*}{ II } & Anahuac 75 & II12300//Lerma Rojo 64/8156/3/Norteno 67 & CIMMYT \\
\hline & MGS 1-Aliança & PF858/OCEPAR1 1 & EPAMIG/UFV \\
\hline & BRS 207 & Seri 82/PF813 & EMBRAPA \\
\hline & VI 98053 & Embrapa 22/BR12 & UFV \\
\hline & UFVT 1-Pioneiro & Veery 5/NACOZARI & UFV \\
\hline & IVI 01041 & TRAP\#1/YACO/3/KAUZ*2/TRAP//KAUZ & UFV \\
\hline
\end{tabular}


No experimento I, foram avaliados os 12 genitores e as 36 populaçóes segregantes na geraçáo $\mathrm{F}_{3}$, sendo as sementes obtidas das populaçôes $\mathrm{F}_{2}$, colhidas em "bulk". Utilizou-se o delineamento em látice $7 \times 7$, com duas repetiçóes, sendo necessária a inclusão de mais um tratamento para completar o látice. As parcelas foram constituídas por cinco linhas de 5,0 m de comprimento, espaçadas em $0,20 \mathrm{~m}$ e densidade de semeadura de 300 sementes aptas por $\mathrm{m}^{-2}$. A área útil foi constituída pelas três linhas centrais da parcela. Neste experimento, coletaram-se dados a serem utilizados na análise de diversidade genética (mensurados apenas nos genitores), na análise dialélica e na média parental.

Para a análise da diversidade genética entre os genitores, foram avaliadas as seguintes características: rendimento de grãos e ciclo até a maturaçáo fisiológica, avaliados com base na área útil da parcela; peso de mil grãos, peso hectolítrico e teor de proteína no grão, avaliados em amostras dos grãos colhidos; comprimento da espiga, número de espiguetas/espiga e número de grãos/espiga, avaliados em dez espigas tomadas ao acaso em cada parcela; e altura de planta, avaliada em cinco plantas amostradas na parcela.

Esses caracteres foram inicialmente submetidos à análise de variância, na qual aqueles que não apresentaram diferença significativa entre os genótipos foram descartados, uma vez que não contribuiriam para as estimativas das distâncias. Em seguida, foi utilizada a distância generalizada de Mahalanobis $\left(\mathrm{D}^{2}\right)$ para quantificar a dissimilaridade entre os genitores conforme apresentado por Cruz et al. (2012). A análise de trilha foi realizada com o intuito de determinar quanto do rendimento de grãos é explicado pelas características utilizadas na determinação da diversidade genética.

As demais análises foram realizadas apenas para o caráter rendimento de grãos. A análise de variância foi feita considerando-se como fixos a média e os efeitos de tratamentos. A soma de quadrados de tratamentos foi desdobrada na soma de quadrados de populaçóes, soma de quadrados de testemunhas e soma de quadrados do contraste populações versus testemunhas. As médias dos tratamentos foram comparadas utilizando-se o teste de Tukey ao nível de $5 \%$ de probabilidade.

Efetuou-se a análise dialélica segundo o modelo de Geraldi e Miranda Filho (1988) para dialelo parcial, adaptado do método de Griffing (1956), com base nas médias ajustadas de tratamento.

A média parental foi obtida pela média aritmética do rendimento médio de grãos dos dois genitores envolvidos em cada cruzamento, conforme apresentado por ANTUNES et al. (1998) da seguinte forma:

$M P(i j)=(P i+P j) / 2$

Em que: $\mathrm{MP}_{(\mathrm{ij})}$ é a média aritmética do rendimento de grãos dos genitores i e j; $\mathrm{P}_{\mathrm{i}}$ é o rendimento médio do genitor $\mathrm{i} ; \mathrm{P}_{\mathrm{j}}$ é o rendimento médio do genitor $\mathrm{j}$.
A eficiência desse método foi averiguada por meio do coeficiente de correlação de Pearson entre a $\mathrm{MP}_{(\mathrm{ij})}$ e a média das respectivas populaçóes, representadas por $\mathrm{F}_{\mathrm{n}}\left(\mathrm{P}_{\mathrm{i}}, \mathrm{P}_{\mathrm{j}}\right)$, em que $\mathrm{F}_{\mathrm{n}}\left(\mathrm{P}_{\mathrm{i}}, \mathrm{P}_{\mathrm{j}}\right)$ é a média da geração $\mathrm{F}_{3}$ do cruzamento entre os genitores i e j.

No experimento II, foram avaliadas as 36 populaçôes segregantes na geração $\mathrm{F}_{3}$ juntamente com as cultivares MGS 1-Aliança, Embrapa 22, UFVT 1-Pioneiro e BRS 264. Os tratamentos foram dispostos em blocos casualizados com informação de indivíduo dentro da parcela, com três repetiçôes para cada tratamento. A parcela experimental foi constituída por duas linhas de 5,0 m de comprimento, espaçadas em $0,20 \mathrm{~m}$ e densidade de dez sementes por metro de sulco.

Em cada parcela, foram colhidas aproximadamente 50 plantas, trilhadas individualmente, determinando-se o rendimento de grãos por planta. Estimou-se a variância fenotípica $\left(\sigma_{\mathrm{F}}^{2}\right)$ de cada parcela e a variância fenotípica média das parcelas que receberam os mesmos tratamentos nas diferentes repetiçôes. A variância genética $\left(\sigma_{\mathrm{G}}^{2}\right)$ de uma dada população 'i’ foi estimada pela seguinte expressão:

$\sigma_{\mathrm{Gi}}^{2}=\sigma_{\mathrm{Fi}}^{2}-\sigma_{\mathrm{E}}^{2}$

Em que: $\sigma_{\mathrm{Gi}}^{2}$ é a variância genética presente na população i; $\sigma_{\mathrm{Fi}}^{2}$ é a variância fenotípica observada na população i; $\sigma_{\mathrm{E}}^{2}$ é a variância ambiental, obtida pela média aritmética da variância fenotípica das cultivares testemunhas presentes no experimento.

A probabilidade de extração de linhagens superiores de cada população foi obtida pela metodologia proposta por Jinks e Pooni (1976). Essa probabilidade corresponde à área à direita de um determinado valor positivo de $Z$ na abscissa da distribuição normal, sendo $Z$ obtida pela expressão:

$\mathrm{Z}=\frac{\overline{\mathrm{L}}-\overline{\mathrm{F}}_{\mathrm{ni}}}{\mathrm{Si}}$

Em que: $\bar{L}$ corresponde à média considerada padrão, que, neste caso, foi a média de rendimento de grãos da cultivar BRS 264 acrescida de $11 \%$, ou seja, $\overline{\mathrm{L}}=8 \mathrm{~g} /$ planta. $\overline{\mathrm{F}}_{\mathrm{ni}}$ é a média de rendimento de grãos das plantas individuais de cada população $\mathrm{F}_{3}$, que, em um modelo sem dominância, corresponde à média de todas as possíveis linhagens na geração $\mathrm{F}_{\infty}$, desde que conduzidas sem seleção. Si é a estimativa do desvio-padrão fenotípico entre as linhagens da geração $\mathrm{F}_{\infty}$.

Os experimentos foram conduzidos em Viçosa, Minas Gerais. O município está localizado nas coordenadas $20^{\circ} 45^{\prime} \mathrm{S}$ e $42^{\circ} 51^{\prime} \mathrm{O}$, com altitude de $650 \mathrm{~m}$. Utilizou-se o sistema de plantio convencional, com semeadura dos 
experimentos realizada na segunda quinzena de maio, utilizando-se como adubaçáo de base a dose de $250 \mathrm{~kg} \mathrm{ha}^{-1}$ da fórmula 08-28-16 no sulco de semeadura e $250 \mathrm{~kg} \mathrm{ha}^{-1}$ de sulfato de amônio, em cobertura, no início do perfilhamento. Para controle de plantas invasoras, aplicou-se o herbicida Ally ${ }^{\circledR}$ aos 15 dias após a semeadura, na dose de $5 \mathrm{~g} \mathrm{ha}^{-1}$ do produto comercial. O controle fitossanitário foi realizado com duas aplicaçôes do fungicida Ópera ${ }^{\circledR}$ na dose de $0,751 \mathrm{ha}^{-1}$ do produto comercial, sendo a primeira realizada na fase final do emborrachamento e a segunda, logo após o espigamento, correspondendo a 15 dias após a primeira aplicação. O cultivo foi conduzido sob irrigação por aspersão convencional.

Em todas as análises estatísticas, foram utilizados os recursos computacionais do Programa Genes (CruZ, 2006).

\section{RESULTADOS E DISCUSSÃO}

No experimento I houve diferença significativa $(\mathrm{p}<0,01)$ entre os tratamentos avaliados quanto ao rendimento de grãos. A partir do desdobramento dessa fonte de variação, verificaram-se existência de diferenças significativas $(\mathrm{p}<0,01)$ tanto entre médias de produtividade das populaçôes segregantes quanto entre os genitores. Para o contraste entre populaçôes e testemunhas, não se verificou diferença significativa.

O melhor desempenho produtivo foi obtido pela população BRS264/VI98053, superando as populações Embrapa22/BRS207, Embrapa42/IVI01041 e a cultivar Anahuac 75 (Tabela 2). A igualdade de desempenho observada entre algumas populaçóes segregantes e cultivares evidencia o potencial de melhoramento dessas populaçóes, com possibilidade de originarem linhagens com desempenho superior aos genitores. Todavia, a produtividade de grãos é um caráter de herança quantitativa, portanto, de distribuição contínua, com maior ou menor distribuição das observaçóes em torno da média, a depender da variabilidade de cada população. Assim, melhor distinção entre a superioridade das populaçóes é obtida pela predição da variabilidade genética dentro de cada população de elevado desempenho.

O coeficiente de correlação de Pearson entre as médias parentais (Tabela 3) e as médias das respectivas populaçóes (Tabela 2) foi de 0,45 ( $\mathrm{p}<0,01)$. Apesar de significativo, a correlação observada apresentou valor moderado, o que diminui a precisão nas predições realizadas a partir do desempenho dos genitores.

A utilização da média parental para predição é fundamentada nas interaçóes aditivas entre alelos. Segundo RAMALHo et al. (2004), quando ocorre esse tipo de interação, a média das geraçóes segregantes é igual à média dos genitores. Contudo, alguns fatores como nível de endogamia, amostragem e fatores externos atuando na seleção podem reduzir a acurácia desse método de predição.
A existência de efeitos epistáticos no controle da produtividade de grãos e seus componentes, conforme constatado para cultura do trigo por Esmail (2007), também pode ocasionar distorção entre os resultados preditos com base na média dos pais e os observados na população. Por esse motivo, apesar de, frequentemente, o bom desempenho das cultivares resultar em bom comportamento como genitores, existe a possibilidade de cruzamentos envolvendo genitores com média alta não apresentarem bom comportamento como genitores (BERTAN et al., 2007; BorÉM e Miranda, 2009). Esse fato pode ter contribuído para redução da magnitude do coeficiente de correlação observado entre a média parental e a média das populaçôes.

A despeito de ser um método comumente utilizado pelos melhoristas de trigo - sobretudo os mais experientes - e de fácil aplicação, a média parental não possibilita antever a variabilidade que será gerada na população. A variabilidade genética de uma população é função do número de diferentes alelos fixados em cada genitor envolvido no cruzamento (RAMALHo et al., 2012). A média parental permite inferir sobre a frequência de alelos favoráveis em cada genitor, mas não é indicativa da frequência de alelos distintos entre os genitores.

Diante dessas considerações, pode-se inferir que a média parental por si só não constitui metodologia eficiente para determinar os cruzamentos que propiciam condiçóes mais favoráveis para seleção de linhagens superiores de trigo.

Na seleção de populaçóes segregantes por meio do dialelo, a escolha é realizada com base nas estimativas da CGC e da CEC, buscando-se identificar populaçóes em que os genitores apresentem elevada estimativa dessas capacidades. Populaçôes que apresentam genitores com esses atributos associam média alta e variabilidade genética de magnitude expressiva, parâmetros fundamentais em uma população destinada à extração de linhas puras (RAMALHo et al., 2012).

Pela análise dialélica, detectou-se diferença significativa para a fonte de variaçáo capacidade geral de combinação dos grupos I e II $(p<0,01)$. A significância dos quadrados médios referentes à CGC demonstra a existência de frequência gênica diferenciada entre os genitores dentro de cada grupo, sendo possível identificar aqueles com maior potencial para gerar combinaçóes híbridas.

Efeitos positivos da CGC foram observados para as cultivares BRS 254, BRS 264 e IAC 364-Tucuruí III, pertencentes ao grupo I, e para as cultivares MGS 1-Aliança, VI 98053 e UFVT 1-Pioneiro, pertencentes ao grupo II (Tabela 2). Valores elevados e positivos para determinado genitor indicam maior concentraçáo de alelos favoráveis ao rendimento de grãos quando comparado com os demais genitores (Cruz et al., 2012).

Os efeitos da capacidade específica de combinação (Tabela 2) foram não significativos $(\mathrm{p}>0,05)$, indicando ausência de variabilidade para essa fonte de variação. Nessa situação, o desempenho dos cruzamentos pode ser previsto com base apenas nas estimativas da CGC (Gomide et al., 2008); logo, as populaçóes mais promissoras são aquelas 
originadas de cruzamentos que envolvam dois genitores com alta CGC pertencentes a grupos distintos. Sendo assim, as populaçóes BRS264/MGS1-Aliança, BRS264/VI98053, BRS264/UFVT1-Pioneiro, IAC364-Tucurí III/MGS1Aliança, IAC364-Tucurí III/VI98053 e IAC364-Tucurí
III/UFVT1-Pioneiro são as que apresentam maior potencial para extração de linhagens superiores.

Das dez melhores populaçóes obtidas com base na média parental (Tabela 3), cinco foram cruzamentos envolvendo dois genitores com alta CGC. As demais combinaçóes

Tabela 2. Efeitos da capacidade geral (CGC) e específica (CEC) de combinação e média do caráter rendimento de grãos obtidos na avaliação de genitores e populaçóes segregantes de trigo, em Viçosa (MG), 2009

\begin{tabular}{|c|c|c|c|}
\hline Genitores/populações & CGC & CEC & Rendimento de grão $\left(\mathrm{kg} \mathrm{ha}^{-1}\right)^{(1)}$ \\
\hline Embrapa 22 & $-97,57$ & - & $2.351 \mathrm{abc}$ \\
\hline Embrapa 42 & $-244,80$ & - & $2.530 \mathrm{abc}$ \\
\hline BRS 254 & 54,28 & - & $2.948 a b c$ \\
\hline BRS 264 & 237,16 & - & $3.116 a b c$ \\
\hline IAC 24-Tucuruí & $-106,57$ & - & $2.554 \mathrm{abc}$ \\
\hline IAC 364-Tucuruí III & 157,50 & - & $3.190 \mathrm{abc}$ \\
\hline Anahuac 75 & $-230,72$ & - & $1.936 \mathrm{bc}$ \\
\hline MGS 1-Aliança & 288,05 & - & $3.320 \mathrm{ab}$ \\
\hline BRS 207 & $-314,64$ & - & $2.129 a b c$ \\
\hline VI 98053 & 115,01 & - & $2.842 a b c$ \\
\hline IVI 01041 & $-50,39$ & - & $3.192 a b c$ \\
\hline UFVT 1-Pioneiro & 192,68 & - & $3.134 a b c$ \\
\hline Embrapa22/Anahuac75 & - & 586,02 & $2.943 a b c$ \\
\hline Embrapa22/MGS1-Aliança & - & $-265,41$ & $2.610 a b c$ \\
\hline Embrapa22/BRS207 & - & $-529,56$ & $1.744 \mathrm{c}$ \\
\hline Embrapa22/VI98053 & - & $-78,21$ & $2.625 a b c$ \\
\hline Embrapa22/IVI01041 & - & 264,69 & $2.802 a b c$ \\
\hline Embrapa22/UFVT1-Pioneiro & - & 323,29 & $3.104 \mathrm{abc}$ \\
\hline Embrapa42/Anahuac75 & - & 158,10 & $2.368 a b c$ \\
\hline Embrapa42/MGS1-Aliança & - & 308,33 & $3.037 \mathrm{abc}$ \\
\hline Embrapa42/BRS207 & - & $-56,66$ & $2.069 a b c$ \\
\hline Embrapa42/VI98053 & - & $-389,48$ & $2.166 a b c$ \\
\hline Embrapa42/IVI01041 & - & $-459,91$ & $1.930 \mathrm{bc}$ \\
\hline Embrapa42/UFVT1-Pioneiro & - & $-206,14$ & $2.427 a b c$ \\
\hline BRS254/Anahuac75 & - & $-179,33$ & $2.330 \mathrm{abc}$ \\
\hline BRS254/MGS1-Aliança & - & $-292,93$ & $2.735 a b c$ \\
\hline BRS254/BRS207 & - & 245,26 & $2.670 \mathrm{abc}$ \\
\hline BRS254/VI98053 & - & 349,94 & $3.205 a b c$ \\
\hline BRS254/IVI01041 & - & $-180,82$ & $2.508 a b c$ \\
\hline BRS254/UFVT1-Pioneiro & - & $-227,56$ & $2.705 a b c$ \\
\hline BRS264/Anahuac75 & - & 17,13 & $2.709 a b c$ \\
\hline BRS264/MGS1-Aliança & - & $-53,81$ & $3.157 \mathrm{abc}$ \\
\hline BRS264/BRS207 & - & $-12,45$ & $2.595 \mathrm{abc}$ \\
\hline BRS264/VI98053 & - & 536,40 & $3.574 \mathrm{a}$ \\
\hline BRS264/IVI01041 & - & $-356,54$ & $2.516 a b c$ \\
\hline BRS264/UFVT1-Pioneiro & - & $-19,61$ & $3.096 a b c$ \\
\hline IAC24Tucuruí/Anahuac75 & - & $-94,48$ & $2.254 a b c$ \\
\hline IAC24-Tucuruí/ MGS1-Aliança & - & 267,59 & $3.134 a b c$ \\
\hline IAC24-Tucuruí/BRS207 & - & 79,94 & $2.344 a b c$ \\
\hline IAC24-Tucuruí/VI98053 & - & $-92,71$ & $2.601 \mathrm{abc}$ \\
\hline IAC24-Tucuruí/IVI01041 & - & $-131,98$ & $2.396 a b c$ \\
\hline IAC24-Tucuruí/UFVT1-Pioneiro & - & $-169,88$ & $2.602 a b c$ \\
\hline IAC364-Tucuruí III/Anahuac75 & - & 66,29 & $2.678 a b c$ \\
\hline IAC364-Tucuruí III/MGS1-Aliança & - & $-103,97$ & $3.027 \mathrm{abc}$ \\
\hline IAC364-Tucuruí III/BRS207 & - & 105,20 & $2.633 a b c$ \\
\hline IAC364-Tucuruí III/VI98053 & - & $-202,93$ & $2.755 a b c$ \\
\hline IAC364-Tucuruí III/IVI01041 & - & $-372,37$ & $2.420 \mathrm{abc}$ \\
\hline IAC364-Tucuruí III/ UFVT1-Pioneiro & - & 150,56 & $3.186 a b c$ \\
\hline
\end{tabular}


apresentaram pelo menos um genitor com estimativa elevada de CGC, exceto o cruzamento BRS254/IVI01041, no qual o BRS 254 apresentou estimativa positiva, porém de baixa magnitude. Logo, observa-se boa concordância entre as prediçôes realizadas usando-se a análise dialélica e a média parental, semelhante ao obtido por Oliveira et al. (1996) com Phaseolus vulgaris. Essa concordância é justificada pelo elevado coeficiente de correlação de Spearman $(\rho=0,81)$ obtido entre o desempenho produtivo dos genitores, variável utilizada para obter a média parental, e a respectiva CGC.

Tabela 3. Média parental (MP), distância generalizada de Mahalanobis $\left(\mathrm{D}^{2}\right)$ e probabilidade de extração de linhagens superiores (P) para o caráter rendimento de grãos de populaçóes segregantes de trigo avaliadas em Viçosa (MG), 2009 $9^{(1)}$

\begin{tabular}{|c|c|c|c|}
\hline Cruzamentos $^{(2)}$ & MP (kg ha-1) & $D^{2}$ & $\mathbf{P}(\%)^{(3)}$ \\
\hline Embrapa22/Anahuac75 & 2.143 & 758 & 34,8 \\
\hline Embrapa22/MGS1-Aliança* & 2.836 & 3.520 & 31,2 \\
\hline Embrapa22/BRS207 & 2.240 & 520 & 38,2 \\
\hline Embrapa22/VI98053 & 2.597 & 120 & 29,8 \\
\hline Embrapa22/IVI01041 & 2.771 & 186 & 30,9 \\
\hline Embrapa22/UFVT1-Pioneiro & 2.743 & 259 & 30,5 \\
\hline Embrapa42/Anahuac75 & 2.233 & 295 & 23,0 \\
\hline Embrapa42/MGS1-Aliança* & 2.925 & 2.014 & 5,1 \\
\hline Embrapa42/BRS207 & 2.329 & 141 & 27,1 \\
\hline Embrapa42/VI98053 & 2.686 & 177 & 29,1 \\
\hline Embrapa42/IVI01041 & 2.861 & 353 & 24,5 \\
\hline Embrapa42/UFVT1-Pioneiro & 2.832 & 130 & 37,1 \\
\hline BRS254/Anahuac75 & 2.442 & 979 & 37,8 \\
\hline BRS254/MGS1-Aliança* & 3.134 & 4.094 & 41,3 \\
\hline BRS254/BRS207 & 2.538 & 709 & 35,2 \\
\hline BRS254/VI98053 & 2.895 & 132 & 30,5 \\
\hline BRS254/IVI01041 & 3.070 & 200 & 37,5 \\
\hline BRS254/UFVT1-Pioneiro & 3.041 & 361 & 33,7 \\
\hline BRS264/Anahuac75 & 2.526 & 1.016 & 40,5 \\
\hline BRS264/MGS1-Aliança* & 3.218 & 3.288 & 16,9 \\
\hline BRS264/BRS207 & 2.622 & 541 & 41,3 \\
\hline BRS264/VI98053 & 2.979 & 121 & 31,6 \\
\hline BRS264/IVI01041* & 3.154 & 363 & 11,1 \\
\hline BRS264/UFVT1-Pioneiro & 3.125 & 84 & 34,1 \\
\hline IAC24-Tucuruí/Anahuac75 & 2.245 & 361 & 17,9 \\
\hline IAC24-Tucuruí/MGS1-Aliança* & 2.937 & 1.547 & 20,3 \\
\hline IAC24-Tucuruí/BRS207 & 2.342 & 64 & 26,4 \\
\hline IAC24-Tucuruí/VI98053 & 2.698 & 425 & 22,1 \\
\hline IAC24-Tucuruí/IVI01041* & 2.873 & 612 & 20,6 \\
\hline IAC24-Tucuruí/UFVT1-Pioneiro & 2.844 & 313 & 38,2 \\
\hline IAC364-Tucuruí III/Anahuac75 & 2.563 & 214 & 40,1 \\
\hline IAC364-Tucuruí III/MGS1-Aliança* & 3.255 & 1.557 & 29,5 \\
\hline IAC364-Tucuruí III/BRS207 & 2.660 & 42 & 34,1 \\
\hline IAC364-Tucuruí III/VI98053* & 3.016 & 388 & 27,4 \\
\hline IAC364-Tucuruí III/IVI01041* & 3.191 & 541 & 28,8 \\
\hline IAC364-Tucuruí III/UFVT1-Pioneiro & 3.162 & 362 & 26,8 \\
\hline
\end{tabular}

Como pela análise dialélica a seleçáo foi realizada considerando apenas a CGC, espera-se concordância com a seleção baseada na média parental, pois ambos os parâmetros são determinados por efeitos gênicos aditivos. Neste estudo, pode-se inferir que o efeito insignificante da CEC se deve à reduzida contribuição dos efeitos de dominância para expressão do caráter na geração analisada, na qual a heterose foi reduzida a $1 / 4$ do seu valor. Tendo em vista que a CEC é função da complementaridade gênica, parâmetro não constatado pela média parental, é provável que, em situações nas quais o efeito da CEC seja significativo, a concordância entre essas metodologias diminua.

A análise de diversidade genética possibilita identificar genitores geneticamente complementares, que, ao serem intercruzados, poderão originar populaçôes com maior variabilidade e com maior probabilidade de recuperação de genótipos superiores (CRUZ et al., 2012).

No estudo de divergência realizado neste trabalho, apenas o teor de proteína no grão não apresentou diferença significativa entre os genitores. Desse modo, dos nove caracteres mensurados, oito foram utilizados para determinação da dissimilaridade entre os genitores. Pela análise de trilha, evidenciou-se que esses caracteres explicam $78 \%$ do rendimento de grãos (Tabela 4).

A amplitude das distâncias entre pares de genitores foi elevada (Tabela 3). Observa-se que, entre as populaçóes avaliadas, encontram-se combinaçóes de genitores que associam média alta e diversidade alta (BRS264/MGS1-Aliança), média baixa e diversidade alta (BRS254/Anahuac75), média alta e diversidade baixa (BRS264/UFVT1-Pioneiro) e média baixa e diversidade baixa (IAC24-Tucuruí/BRS207). Isso evidencia que a divergência genética isoladamente não é suficiente para prediçáo do potencial de populaçóes, pois considera apenas a diferença na frequência alélica, e não a quantidade de alelos favoráveis. Nota-se que o inverso é válido para a utilização da média parental isoladamente, ou seja, seu uso prevê a quantidade de alelos favoráveis, mas não prevê a diferença na frequência alélica.

De acordo com Abreu et al. (1999), a alta frequência de locos em heterozigose originados de alta divergência não compensa a baixa frequência de alelos favoráveis. Sendo assim, a seleção com base na distância genética deve ser sempre ponderada pela média dos genitores envolvidos.

Considerando-se as dez melhores populaçôes selecionadas com base na presença de genitores divergentes e com média parental elevada (Tabela 3), evidenciou-se que todos os cruzamentos, exceto IAC24-Tucuruí/IVI01041, apresentaram pelo menos um genitor com alta CGC, indicando certo grau de concordância entre as metodologias. Entretanto, mesmo considerando-se o desempenho médio junto com a diversidade para seleçấo de genitores, os resultados observados nas progênies podem não ser os previstos, tendo em vista as consideraçóes feitas pertinentes à seleção baseada na média parental. 
Segundo BorÉm e Miranda (2009), alguns cruzamentos tendem a causar desorganizaçáo na estrutura gênica do germoplasma, com significativa redução no comportamento geral da população originada, enquanto, em outros, os genomas envolvidos parecem complementar-se perfeitamente. Esse é o motivo pelo qual verifica-se incoerência entre as prediçóes e os valores observados quando se utilizam estimativas obtidas apenas a partir dos genitores.

Além disso, a utilização da média parental associada à diversidade genética implica em necessidade de realizar experimentos para mensurar as variáveis a serem utilizadas na análise de diversidade entre os possíveis genitores, o que acarreta mais trabalho a cada composição de blocos de cruzamentos.

Diante dessas consideraçôes, a capacidade de combinação entre os genitores pode ser uma medida mais acurada para a seleção de genitores e populaçôes superiores, pois os parâmetros genéticos são estimados com base nas progênies e nos genitores.

A principal dificuldade apresentada na incorporação da análise dialélica na rotina dos programas de melhoramento de espécies autógamas é o trabalho despendido na realização dos cruzamentos, sobretudo quando estão envolvidos muitos genitores. No entanto, existem esquemas de dialelo, como o parcial e o circulante, que permitem a avaliação de um conjunto relativamente grande de genitores sem a necessidade de realizar todas as combinaçôes possíveis entre os genitores presentes no dialelo. Ademais, por meio da análise dialélica, é possível determinar a ação gênica que controla a caráter (Cruz et al., 2012), a qual auxilia o melhorista na escolha do método de condução das populações e do critério de seleção a ser adotado.

No experimento II, em que foram avaliadas plantas dentro de populaçôes, não foi constatado efeito significativo de genótipos $(\mathrm{p}>0,05)$, indicando igualdade entre médias de rendimento de grãos dos tratamentos.

Esse resultado, divergente em relação ao observado no experimento I, pode ser explicado pela diferença na forma de condução das plantas, que, neste caso, foram mais espaçadas. Segundo Snape (1982), para que os resultados sejam coerentes, é necessário que exista associação para o caráter em questão entre o cultivo em plantas espaçadas e o cultivo em linha cheia. Neste trabalho, a correlação entre médias de rendimento de grãos dos tratamentos nos dois sistemas de cultivo foi de apenas $11 \%$. Assim, a inexistência de diferença significativa entre as médias das populações no experimento II foi decorrente do expressivo efeito de ambiente, onde os genótipos puderam expressar todo seu potencial na ausência de competição. Em estudos realizados por Vieira et al. (2007) e Bertan et al. (2009), também foram encontrados resultados divergentes em análises realizadas a partir de caracteres mensurados em trigo cultivado em linhas cheias e plantas espaçadas.

Com a aplicação da metodologia de Jinks e Pooni (1976), as populaçóes que apresentaram maior probabilidade de extração de linhagens superiores foram BRS264/BRS207 e BRS254/MGS1-Aliança (Tabela 3).

Comparando-se os resultados desta metodologia com aqueles obtidos pela análise dialélica e média parental, verifica-se que não houve concordância entre eles. Pode-se observar que, entre as cinco populações com menores chances de gerar linhagens superiores, encontra-se a combinaçáo BRS264/MGS1-Aliança, considerada como uma das melhores pelos demais métodos. Essa população é constituída por genitores com as maiores CGC, divergentes entre si e com média parental elevada.

A metodologia de Jinks e Pooni (1976) tem sua eficiência comprovada por diversos trabalhos (Triller e Toledo, 1996; Santos et al., 2001). Contudo, quando as estimativas dos componentes genéticos são obtidas por meio de avaliações em plantas individuais, os resultados sáo menos precisos devido à maior amplitude dos erros associados a esse tipo de estimativa (ABREU et al., 2002). Pela análise dos dados obtidos, verificaram-se estimativas negativas da variância genética para algumas populaçôes,

Tabela 4. Estimativas dos efeitos diretos e indiretos de sete características agronômicas sobre o rendimento de grãos, obtidas pela análise de trilha, em dez genótipos de trigo em Viçosa (MG), 2009

\begin{tabular}{lccccccc} 
Efeitos $^{(1)}$ & \multicolumn{7}{c}{ Variáveis explicativas } \\
\cline { 2 - 8 } & ALT & MAT & NEE & NGE & CE & PH & PMG \\
\hline Direto & $-0,5855$ & $-0,3852$ & 0,4148 & 0,2331 & $-0,9765$ & 0,6005 & 0,0007 \\
\hline Indireto via ALT & - & 0,1554 & 0,0334 & 0,2184 & 0,2681 & $-0,2322$ & 0,0506 \\
\hline Indireto via MAT & 0,1022 & - & $-0,2372$ & $-0,1184$ & $-0,1168$ & 0,2549 & 0,1028 \\
\hline Indireto via NEE & $-0,0237$ & 0,2554 & - & $-0,0240$ & 0,1535 & $-0,2336$ & $-0,0555$ \\
\hline Indireto via NGE & $-0,0869$ & 0,0716 & $-0,0135$ & - & 0,1229 & $-0,0799$ & $-0,1091$ \\
\hline Indireto via CE & 0,4472 & $-0,2961$ & $-0,3614$ & $-0,5150$ & - & 0,1557 & 0,3478 \\
\hline Indireto via PH & 0,2382 & $-0,3974$ & $-0,3382$ & $-0,2059$ & $-0,0957$ & - & 0,2599 \\
\hline Indireto via PMG & $-0,0001$ & $-0,0002$ & $-0,0001$ & $-0,0003$ & $-0,0002$ & 0,0003 & - \\
\hline Total & 0,0915 & $-0,5966$ & $-0,5021$ & $-0,4122$ & $-0,6447$ & 0,4657 & 0,5973 \\
\hline Coeficiente de determinação: 0,7815 & & & & & & &
\end{tabular}

(1) ALT: altura de planta; MAT: maturação; NEE: número de espiguetas/espiga; NGE: número de grãos/espiga; CE: comprimento da espiga; PH: peso hectolítrico; PMG: peso de mil grãos. 
evidenciando a existência de viés na estimação dos parâmetros a partir da análise de plantas individuais.

De acordo com SnAPE (1982), a ocorrência desse tipo de erro em trigo é fruto da dificuldade de avaliar as variaçóes genéticas para a produção e seus componentes por causa dos efeitos da competição dentro da parcela. Resultados semelhantes foram observados por MendonçA et al. (2002) em feijáo. Esses autores apontam que, apesar de o método de Jinks e Pooni (1976) ser adequado, a utilização de estimativas de variância obtidas de plantas individuais gera problemas de baixa precisão experimental e dificuldade na obtenção de dados.

No caso da cultura do trigo, a obtençấo de dados de plantas individuais, além de ocasionar a obtenção de estimativas de variância genética negativa, é dificultada devido à densidade de plantio recomendada para a cultura e o intenso afilhamento. $\mathrm{Na}$ densidade comercial de semeadura, é impossível a individualização de plantas. Assim, para a aplicação da metodologia de Jinks e Pooni (1976), é necessário que a semeadura seja realizada em menores densidades, o que origina a necessidade de condução de experimentos específicos para esses fins.

\section{CONCLUSÃO}

A média parental e a diversidade genética isoladamente náo constituem método de prediçấo eficiente para a seleção de populaçôes segregantes. A aplicação da metodologia de Jinks e Pooni (1976), a partir de estimativas obtidas em plantas espaçadas, apresenta limitação de ordem prática na cultura do trigo. A análise dialélica constitui o método de predição mais promissor para determinação de genitores e populaçóes segregantes superiores.

\section{AGRADECIMENTOS}

Ao Conselho Nacional de Desenvolvimento Científico e Tecnológico, pelo apoio financeiro, e à Coordenação de Aperfeiçoamento de Pessoal de Nível Superior, pela concessão da bolsa de estudo.

\section{REFERÊNCIAS}

ABREU, A.F.B.; RAMALHO, M.A.P.; FERRREIRA, D.F. Selection potential for seed yield from intra- and inter-racial populations in common bean. Euphytica, v.108, p.121-127, 1999.

ABREU, A.F.B.; RAMALHO, M.A.P.; SANTOS, J.B. Prediction of seed-yield potential of common bean populations. Genetics and Molecular Biology, v.25, p.323-327, 2002.

ANTUNES, I.F.; VELLO, N.A.; TEIXEIRA, M.G.; SILVEIRA, E.P.; EMYGDIO, B.M.; ZONTA, E.P. Predição da produtividade de grãos de populaçóes $F_{2}$ de feijão a partir da média parental.
Ciência Rural, v.28, p.357-360, 1998. DOI: 10.1590/S010384781998000300001

BARELLI, M.A.A.; VIDIGAL, M.C.G.; AMARAL JÚNIOR, A.T.; VIDIGAL FILHO, P.S.; SCAPIM, C.A.; SAGRILO, E. Diallel analysis for grain yield and yield components in Phaseolus vulgaris $\mathrm{L}$. Acta Scientiarum Agronomy, v.22, p.883-887, 2000.

BARROSO, P.A.V.; HOFFMANN, L.V. Métodos de predição do comportamento de populaçóes de melhoramento. Campina Grande: Embrapa Algodão, 2003. 38p. (Embrapa Algodáo. Documentos, 108)

BERTAN, I.; CARVALHO, F.I.F.; OLIVEIRA, A.C. Parental selection strategies in plant breeding programs. Journal of Crop Science and Biotechnology, v.10, p.211-222, 2007.

BERTAN, I.; CARVALHO, F.I.F.; OLIVEIRA, A.C.; BENIN, G.; VIEIRA, E.A.; VALÉRIO, I.P. Morphological, pedigree, and molecular distances and their association with hybrid wheat performance. Pesquisa Agropecuária Brasileira, v.44, p.155$163,2009$.

BORÉM, A.; MIRANDA, G.V. Melhoramento de plantas. 5.ed. Viçosa: UFV, 2009. 529p.

COMISSÃO BRASILEIRA DE TRIGO E TRITICALE. Informaçôes técnicas para a safra 2008: Trigo e Triticale. Londrina: Embrapa Soja, 2008. 147p. (Embrapa Soja. Documentos 301)

CRUZ, C.D. Programa Genes - Aplicativo computacional em Genética e Estatística Experimental. 2006. Disponível em: <http// www.ufv.br/dbg/genes/genes.htm>. Acesso em: 27/5/2013.

CRUZ, C.D.; REGAZZI, A.J.; CARNEIRO, P.C.S. Modelos biométricos aplicados ao melhoramento genético. 4.ed. Viçosa: UFV, 2012. 514p.

ESMAIL, R.M. Detection of genetic components through triple test cross and line $\mathrm{x}$ tester analysis in bread wheat. World Journal of Agricultural Sciences, v.3, p.184-190, 2007.

GERALDI, I.O.; MIRANDA-FILHO, J.B. Adapted models for the analysis of combining ability of varieties in partial diallel crosses. Brazilian Journal of Genetics, v.11, p.419-430, 1988.

GOMIDE, M.L.; MALUF, W.R.; GOMES, L.A.A. Capacidade de combinação de linhagens elite de pimentão (Capsicum annuum L.). Ciência e Agrotecnologia, v.32, p.740-748, 2008. DOI: 10.1590/ S1413-7054200800300006

GRIFFING, B. Concept of general and specific combining ability in relation to diallel crossing systems. Australian Journal of Biological Sciences, v.9, p.463-493, 1956.

JINKS, J.L.; POONI, H.S. Predicting the properties of recombinant inbred lines derived by single seed descent. Heredity, v.36, p.253266, 1976. DOI: 10.1038/hdy.1976.30

LORENCETTI, C.; CARVALHO, F.I.F; BENIN, G.; MARCHIORO, V.S.; OLIVEIRA, A.C.; SILVA, J.A.G.; HARTWIG, I.; SCHMIDT, D.A.M.; VALÉRIO, I.P. Capacidade 
combinatória e heterose em cruzamento dialélico de aveia (Avena sativa L.). Revista Brasileira de Agrociência, v.11, p.143-148, 2005.

LORENCETTI, C.; CARVALHO, F.I.F.; OLIVEIRA, A.C.; VALÉRIO, I.P.; VIEIRA, E.A.; SILVA, J.A.G.; RIBEIRO, G. Estimativa do desempenho de progênies $\mathrm{F}_{2}$ e $\mathrm{F}_{3}$ com base no comportamento dos genitores e dos híbridos $\mathrm{F}_{1}$ em aveia. Bragantia, v.65, p.207-214, 2006. DOI: 10.1590/S0006-8705200600020003

MENDONÇA, H.A.; SANTOS, J.B.; RAMALHO, M.A.P. Selection of common bean segregating populations using genetic and phenotypic parameters and RAPD markers. Crop Breeding and Applied Biotechnology, v.2, p.219-226, 2002.

OLIVEIRA, L.B.; RAMALHO, M.A.P.; ABREU, A.F.B.; FERREIRA, D.F. Alternative procedures for parent choice in a breeding program for the common bean (Phaseolus vulgaris L.). Brazilian Journal of Genetics, v.19, p.611-615, 1996. DOI: 10.1590/ S0100-84551996000400014

PEREIRA, H.S.; SANTOS, J.B.; ABREU, A.F.B.; COUTO, K.R. Informaçóes fenotípicas e marcadores microssatélites de QTL na escolha de populaçóes segregantes de feijoeiro. Pesquisa Agropecuária Brasileira, v.42, p.707-713, 2007. DOI: 10.1590/ S0100-204x2007000500014

RAMALHO, M.A.P.; SANTOS, J.B.; PEREIRA FILHO, I.A. Choice of parents for dry bean (Phaseolus vulgaris L.) breeding. I. Interactions of mean components by generation and by location. Revista Brasileira de Genética, v.11, p.391-400, 1988.

RAMALHO, M.A.P.; SANTOS, J.B.; PINTO, C.A.B.P. Genética na agropecuária. 3.ed. Lavras: UFLA, 2004. 472p.
RAMALHO, M.A.P.; ABREU, A.F.B.; SANTOS, J.B.; NUNES, J.A.R. Aplicaçóes da genética quantitativa no melhoramento de plantas autógamas. Lavras: UFLA, 2012. 522p.

SANTOS, P.G.; SOARES, A.A.; RAMALHO, M.A.P. Predição do potencial genético de populaçóes segregantes de arroz de terras altas. Pesquisa Agropecuária Brasileira, v.36, p.659-670, 2001. DOI: 10.1590/S0100-204x2001000400009

SNAPE, J.W. Predicting the frequencies of transgressive segregants for yield and yield components in wheat. Theoretical and Applied Genetics, v.62, p.127-134, 1982. DOI: 10.1007/BF00293344

SPRAGUE, G.F.; TATUM, L.A. General vs. specific combining ability in single crosses of corn. Journal of the American Society of Agronomy, v.34, p.923-932, 1942.

TRILLER, C.; TOLEDO, J.F.F. Using the $\mathrm{F}_{3}$ generation for predicting the breeding potential of soybean crosses. Brazilian Journal of Genetics, v.19, p.289-294, 1996.

VALÉRIO, I.P.; CARVALHO, F.I.F.; OLIVEIRA, A.C.; SOUZA, V.Q.; BENIN, G.; SCHMIDT, D.A.M.; RIBEIRO, G.; NORNBERG, R.; LUCH, H. Combining ability of wheat genotypes in two models of diallel analyses. Crop Breeding and Applied Biotechnology, v.9, p.100-107, 2009.

VIEIRA, E.A.; CARVALHO, F.I.F; BERTAN, I.; KOPP, M.M.; ZIMMER, P.D.; BENIN, G.; SILVA, J.A.G.; HARTWIG, I.; MALONE, G.; OLIVEIRA, A.C. Association between genetic distances in wheat (Triticum aestivum L.) as estimated by AFLP and morphological markers. Genetics and Molecular Biology, v.30, p.392-399, 2007. DOI: 10.1590/S1415-47572007000300016 